\title{
(EX)POSIÇÕES DE UM CORPO VIBRÁTIL: CONSIDERAÇÕ̃ES SOBRE CORPO E HUMANIZAÇÃO
}

Resumo: Ao abordar as dimensões sensoriais e estéticas, este texto destaca experiências e narrativas nas quais é possível explicitar movimentos e relações entre corpo e humanidade. Conhecer histórias e procedimentos de uma negação não deve nos impedir de rememorar seus artifícios mais sutis ou duvidar de suas reelaborações, pelo contrário. Talvez, seja imprescindível suscitar as marcas e os procedimentos de uma negação, que se embaralham e ao se confundir, fazem perpetuar suas impregnações. E talvez seja ainda mais urgente trazer ao jogo algumas táticas e noções que não se rendem à lógica que tenta deter a dinâmica de um corpo em movimento, que se reinventa nas dimensões de seus silêncios, ressonâncias e vibrações, e não cede aos dispositivos de captura de sua humanidade.

Palavras-chave: Educação; Estética; Ressonância.

\section{(EX) POSICIONES DE UN CUERPO VIBRABLE: CONSIDERACIONES DE CUERPO Y HUMANIZACIÓN.}

Resumen: Al abordar las dimensiones sensoriales y estéticas, este texto resalta experiencias y narrativas en las cuales es posible explicar movimientos y relaciones entre el cuerpo y la humanidad. Conocer historias y procedimientos de una negación no debería impedirnos recordar sus dispositivos más sutiles o dudar de sus reelaboraciones, por el contrario. Quizás, es esencial elevar las marcas y los procedimientos de una negación, que se barajan y confunden, perpetúan sus impregnaciones. Y quizás sea aún más urgente poner en juego algunas tácticas y nociones que no ceden ante la lógica que intenta disuadir la dinámica de un cuerpo en movimiento, que se reinventa en las dimensiones de sus silencios, resonancias y vibraciones, y no cede ante dispositivos de captura de tu humanidad.

Palabras clave: Educación; Estética; Resonancia.

\section{Desumanização em curso}

À beira do que parecia um precipício, a fala de uma professora ${ }^{3}$ reiniciaria também aqui seus ecos: "Há uma desumanização em curso. O que nossas pesquisas tem a ver com isso?" 
Os sentidos de humanidade não dizem respeito apenas ao que é ou não um ato humano. Mas que desses atos, desses gestos, ou até mesmo os traços e costumes, venham a definir quem é ou não humano. Essa disputa pelo sentido de humanidade já serviu como álibi (sic) ao longo da história para escravizar, para promover holocaustos e genocídios. Retirar os traços de humanidade, remover a humanidade de alguém, serve nesta lógica como justificativa para realizar desumanidades.

O paradoxo parece não incomodar aqueles que se aprazem com doses de retorno à era medieval. Parece fazer regozijar aqueles que defendem que haja divisões entre quem tem direitos e aqueles que, a priori não os tenham.

Quem tem direito aos direitos humanos? As realidades que se apresentam provocam essa pergunta, aparentemente redundante, e respondem fora da obviedade. Todos os humanos, seria uma resposta óbvia. Eé aí que o subterfúgio de desumanizar para justificar desumanidades disputa o sentido na própria falta de lógica.

Candido (2017) atenta ao fato de que, embora as tecnologias alcançadas teoricamente possibilitem a igualdade e a justiça, é desalentador perceber uma realidade inversa em relação à luta pelos direitos humanos. E se o discurso não condiz com as barbáries que continuam a acontecer, se as injustiças e as misérias ainda existem - prossegue o autor - ao menos não são motivos para exaltação, mas sim para serem disfarçadas.

Eis um primeiro aspecto a ser observado com atenção diferenciada em relação ao que observou Candido no contexto de sua escrita. Há hoje um movimento despudorado no Brasil em relação às injustiças, às minorias, às misérias. Um movimento que não se constrange em se revelar reacionário, intolerante, segregador. Menos que constrangido, se exibe aos aplausos. Um movimento que do ângulo otimista provoca o repúdio dos mais esclarecidos por tais atitudes vindas de dirigentes políticos. E que esse esclarecimento ainda é manifestado por muitos. Mas ainda é preciso se aproximar e empenhar mais atenção com a questão. Ou talvez dar uns passos atrás para observar a paisagem da disputa.

Das coisas menos óbvias e ligadas à ordem da legalidade, à ordem do direito, pensar em direitos humanos, discorre Candido (2017), é pressupor que aquilo que é indispensável para uns, é igualmente indispensável para o próximo. E incluir o semelhante no rol dos direitos é afirmar que a priori há igualdade, que a priori há humanidade.

A humanização para Candido (2017)

é o processo que confirma no homem aqueles traços que reputamos essenciais, como o exercício da reflexão, a aquisição do saber, a boa disposição para com o próximo, o afinamento das emoções, a capacidade de penetrar os problemas 
da vida, o senso da beleza, a percepção da complexidade do mundo e dos seres, o cultivo do humor ( Idem, p. 182)

Para Freire (in KIMIECIKI, 2010), o ser humano se caracteriza por sua capacidade de reflexão, por sua incompletude e, especialmente, pela consciência desse inacabamento. Analisar, comparar, romper, decidir, dentre tantas capacidades humanas, são possíveis e se fazem através das relações com os outros, consigo e com o mundo, no mundo. A humanização é o processo que confirma a humanidade e constrói novos sentidos, novas formas de intervir no mundo, para que este mundo seja também novo. Por ser algo feito em relação a algo - prossegue Freire - é coletivo, é construção social, e não individual.

Quando Candido (2017) traz sua noção de humanização, ele discorre sobre o direito à literatura como um direito humano, pois desenvolve uma medida de humanidade. Não uma literatura que alcança sua função quanto mais se aproxime daquilo que compreende como a verdade, castigando ou premiando. Mas uma literatura que se aproxima do senso estético; da capacidade de criar e fazer criar; de visibilizar; de trazer ao jogo figuras até então tratadas de formas caricatas sob outras perspectivas. Uma literatura que desperta e desenvolve a ampliação do sensível, da humanidade. E neste sentido, ser humano é um direito humano.

Um corpo que é detido ao campo da saúde revela uma espécie de ausência que lhe dá significado e ao mesmo tempo retira sentidos. Um corpo que desencadeia suas relações com a morte e com a vida biológica, é o mesmo corpo que no espaço de formação educacional deriva de um projeto específico de ser humano que se pretende forjar. O que pesquisas sobre corpo combatem ou contribuem com a desumanização em curso?

\section{Pactos silenciosos $^{4}$}

O vento na grande área aberta não amenizava o calor. Soprava quente como de costume. Eu não entendia muito bem o porquê daquele espaço tão grande, mas ainda assim achava bonito. Uma beleza que estava relacionada à estética do lugar e suas árvores opacas pelo verão, e pura e simplesmente pelo que provocava: por me sentir conectada àquele espaço da zona oeste do Rio de Janeiro.

Meu pai raramente me segurava pela mão onde quer que fosse. Neste dia, ao me soltar, me adiantei para acompanhar meu irmão mais velho em seus passos apressados e andamos lado a lado sob um céu interminável. Antes de chegar ao nosso destino, podíamos ver por toda parte 
fileiras e fileiras de pessoas. Todas que as formavam, estáticas, pareciam ignorar o sol sobre suas vestes pesadas. Precisávamos passar antes que começassem a hastear a bandeira. Caso contrário, deveríamos permanecer onde quer que estivéssemos e cantar o hino nacional como todos ali presentes. Em silêncio, passo a passo, deixando para trás cada uma daquelas pessoas, agradecia intimamente por não ter nascido menino. E lamentava a possibilidade de ver um dia meu irmão perfilado como todos aqueles soldados, em nome de algo que eu entendia, sem alcançar compreensão alguma, porém.

Depois de ver como era um helicóptero por dentro no dia de meio expediente do nosso pai, civil na instituição militar, voltamos à nossa cidade, na baixada fluminense, e ele me deixou na escola. Ninguém para segurar ou soltar minha mão, ninguém cujo afeto me fizesse perseguir ou andar lado a lado em ritmo acelerado. E não havia ali nenhum privilégio em ter nascido menina. Pelo contrário.

Influenciada por momentos históricos marcantes como o recente fim da ditadura no Brasil, a escola onde eu estudava ignorava prelúdios de uma nova era. O Hino Nacional Brasileiro e o da Independência eram o ritual diário no pátio descoberto, salvo nos dias de chuva. Cantávamos com os membros bem alinhados pelo corpo, os pés rigorosamente juntos fiscalizados por alguém da inspetoria que tento sem sucesso lembrar se era homem ou mulher. Não era permitido olhar nada além da nuca do aluno imediatamente à frente. Salvo as vestes e armas, enfileirados como os soldados que eu vira na base aérea. Dispositivos que obedeciam a economias inconfessáveis. Como elucida Foucault (2014), arranjos sutis de aparência inocente, submetendo-nos através da docilidade de nossos corpos. Ao término, seguíamos para nossas salas, rezávamos o pai nosso de olhos bem fechados para, logo em seguida, sermos arguidos nas tabuadas de todas as operações fundamentais. As multiplicações eu sabia e levantava sem medo de responder. Rezar não, e fechava os olhos mentindo minha fé em um deus que eu não sabia se era o meu, apenas desejando que a professora não percebesse o meu balbuciar vazio.

Sentindo-me triste e comedida por horas seguidas, aguardava pelo aviso sonoro das cinco da tarde - hora em que eu poderia voltar a ser a minha versão favorita de mim mesma.

Era um tempo espaço de pique pega na rua, de dar voltas no quarteirão de bicicleta. Tempo de brinquedos sem tantas especificações de uso; de voltar para casa no horário combinado orientados pelo céu, ou pela fome. O tempo parecia ser mais lento em colaborar com as horas descomprometidas de brincadeiras e risos, mas tudo terminava na hora de ir para a escola. Era como se alguém pudesse ser duas pessoas: uma dentro da escola e outra fora dela. 


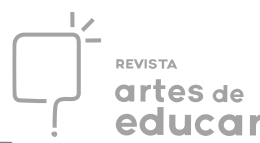

A minha resistência à escola apenas era traduzida e percebida ao final de cada bimestre onde eu só conseguia um índice aceitável em leitura e estudos sociais. As notas baixas fizeram minha mãe recorrer à professora que havia me alfabetizado na escola anterior para reforçar o que era ensinado. E lá estava eu, sem forças, sendo moldada a pertencer àquele espaço, a dar o que me pediam. Sem nenhuma pretensão que me tornasse capaz de perceber os muros edificados em mim e menos ainda em como ou quando poderiam se tornar transponíveis.

Sentados todos os dias no mesmo lugar. O recreio era suficiente para lanchar e tentar não ser pego correndo pela inspetoria. Correr não era permitido: A disciplina é uma anatomia política do detalhe (Idem, 2014, p.137). Semana após semana, eu era quantificada em meus rendimentos, reduzida a ser o número vinte e quatro da chamada, ou a "dois" - a segunda de um nome repetido na chamada.

Iniciado o quarto ano letivo naquela mesma escola, eu estava enfim adaptada a ser duas. Entrei no jogo. Naquele ano, lembro que a coordenadora prometeu que faríamos algo diferente às vésperas do dia das mães. Imaginei que pudesse ser bom, já que eu me envergonhava de dar à minha mãe aqueles presentes de Amélia $^{5}$ - como ela costumava classificar as minhas esforçadas tentativas em personalizar panos de prato e afins.

Turma por turma, dos mais velhos aos mais novos, fomos convidados para ir à outra sala e preparar o tão esperado presente. O quinto ano seria o primeiro, o que me poupou bastante ansiedade. Para minha surpresa e curiosidade, vi uma fila antes da porta. Entraríamos em pequenos grupos e isso me livraria de um vexame diante de toda a classe, o que quer que fosse. Todos meus temores cederam ao inesperado quando, ao entrar na sala me deparei com o que, para mim, era algo terrível: uma equipe de fotógrafos e maquiadores. Como escaparia?

As garotas mais desinibidas da turma ficaram empolgadíssimas diante de todas aquelas possibilidades de maquiagem e de fazer uma foto com um profissional. Tudo que me vinha à cabeça era a voz do Charlie Brown ${ }^{6}$ se lastimando enquanto meus pés seguiam sem perspectiva alguma de salvação.

Todas aquelas cores e texturas de maquiagem faziam com que eu me sentisse profundamente tensa e humilhada. Em minha cabeça ouvia a voz de minha mãe e suas classificações sobre mulheres que usavam pintura no rosto. E pensando bem na solidão, era uma sorte que os meus amigos, vizinhos e primos não estudassem comigo para presenciar as pequenas doses de tirania às quais era submetida. Eu não queria estar ali, ninguém tinha me perguntado se eu queria. 
A foto em si não foi tão ruim. Lembro que uma das fotógrafas me liberou bastante rápido. Eu entendi que haviam desistido de mim - e isso era indescritivelmente ótimo. $\mathrm{O}$ problema é que talvez minha mãe ficasse tão encantada com minha foto como ficaria com um pano de prato.

Passado o que deveria ser o auge da tortura, voltamos à rotina de aulas. A professora "sugeriu" que eu não tirasse a maquiagem. Talvez para não perder mais tempo, talvez porque realmente achasse que estávamos bem. Eu não estava. E lembrar a tabuada de cor com os meninos implicando com o que estava no lugar do meu rosto não era bem uma rotina.

Bendita, a maldita maquiagem disfarçou minha vergonha quando a coordenadora bateu à porta e, ao pedir licença à professora, disse que precisava de minha presença na sala da fotografia por alguns instantes. "O que eu fiz de errado?" - pensava. Eu olhava da turma para a professora em protesto. "Por que só eu?"

Não havia respostas, não tinha coragem de perguntar. Seguia em silêncio resignado os passos dos saltos barulhentos da coordenadora. Ao cruzar a porta já esperando o pior mais uma vez, qual não foi minha surpresa ao ver minha irmã, que estava na classe de pré-alfabetização, de braços cruzados travando a fila da maquiagem simplesmente porque não queria passar o batom rosa. Ela queria o vermelho.

Tendo os olhos arregalados como se fossem saltar das órbitas em um misto de pânico, satisfação e vergonha, permaneci estática com o olhar fixo em minha irmã, que sequer me olhava. A coordenadora e toda a equipe de fotografia olhavam de minha irmã para mim em uma expectativa que não fazia jus ao que eu poderia oferecer naquela situação. Eu mal era capaz de dizer bom dia e boa tarde em voz alta na escola. Ainda assim, reuni toda a dignidade que me faltara horas antes para recusar aquele estúpido batom que eu não queria em mim de cor alguma e o blush (deus, o que era aquele blush?!) - como se alguém tímida como eu precisasse de mais rubor. Sem mais pensar, fui de apoio à minha irmã. Engoli em seco e disse: "Ela quer o vermelho, não pode ser o vermelho?" - foi tudo. E foi pouco. A resposta foram olhares decepcionados e cabeças balançando negativamente. Por fim, uma maquiadora esclareceu que batom vermelho simplesmente não ficaria bem em uma criança de cinco anos de idade. Por que e para quem estava disponível ali, nunca soube. Naquela "verdade absoluta e incontestável" da cor de um batom eu via como as pessoas se ocupavam em ser subjetivas com elas mesmas e terrivelmente objetivas conosco e consequentemente nos tiravam nossa individualidade, nossa subjetividade, nossos quereres - como bem me lembra Santos (2011). Naquele batom eu via meus próprios pés ao som do hino nacional, via a nuca de um menino em meio às minhas 


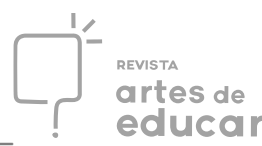

lágrimas que não podiam cair, pois era recorrentemente colocada na fila dos meninos como castigo. Castigo porque gostava de correr, de conversar com eles e porque às vezes eu gostava de usar os tênis antigos de meu irmão ao invés de melissas.

"Por que não pode olhar pro lado? Eu não sou um menino só porque gosto de correr! Melissa escorrega! Pra que tanto espaço no quartel? Meu irmão odeia hastear a bandeira, tira ele daí! Eu não sei rezar! Por que não pode ser vermelho?"

Nenhuma dessas frases foi dita. Ao escrevê-las, saem de mim. Mas nunca me deixam.

Eu me sentia tão impotente quanto minha irmã zangada. Quando por fim percebeu a batalha perdida pela cor desejada, estava no local assinalado para a fotografia, aos holofotes e olhares de toda a equipe. Você tem que sorrir - disse a fotógrafa. Mas eu não vou - esclareceu sem dizer palavra alguma, ao endurecer suas feições e projetar em seus lábios borrados de rosa a raiva que durou muito mais que a foto precisava para ser feita.

Saí da sala quando indicada à porta, deixando minha irmã aos lobos. Ela sabia se defender melhor que eu, era bem verdade. Mas eu me sentia recorrentemente muito infeliz naquela escola. Se eles sequer escutavam minha irmã em sua rebeldia anunciada por suas palavras categóricas e decididas, como poderiam considerar aquilo que eu pensava quando raramente usava minha voz?

A exclusão das diferenças por aquela grotesca maquiagem não nos trazia igualdade, mas nos tornava seriados, padronizados. Os meninos escapavam da maquiagem, mas não dos penteados. Era tanta goma, gel, ficavam todos iguais. Patéticos, mas estavam muito ocupados se divertindo à custa daquela tinta que estava no lugar de nossas expressões. Todos, meninos e meninas, subordinados aos passos da trôpega democracia daqueles educadores que haviam vivido desde os gestos mínimos a sua privação.

A imortalização deste momento se iniciou no instante em que o pretenso objeto da fotografia, minha irmã, tornou claro que era sujeito de si mesma, pronunciando sua perspectiva diante da padronização que pretendiam todos aqueles profissionais. A advogada que se tornaria, tomou para si seu maior direito antes mesmo de ser alfabetizada.

Ainda que sem consciência do que estava provocando, ela não pretendia se transformar numa fotografia, mas sim a fotografia deveria se transformar nela. Dependêssemos daqueles adultos que conduziram a situação, seríamos mais felizes e respeitados em nossa individualidade se estivéssemos a personalizar os estúpidos presentes para vestir as cozinhas de nossas casas. Essa era a função dos presentes: trazer a possibilidade de todos presentearem suas queridas mães de maneira igualitária, ainda que tornassem todos iguais - filhos e mães. Essa 
era a contraditória função dos presentes: produzir ausências. Quando fracassaram, como no caso de minha irmã, produziram os mais autênticos resultados.

Já a minha fotografia era uma tradução fiel aos dias que passamos enfileirados diante da bandeira sob o sol escaldante da cidade- desconsideradas, eu e a terra da laranja em seu clima nunca europeu. Lá estamos as duas mortificadas. Tomaram-me de empréstimo para ser retratada justo em minha versão escolar, a que me sentia menos eu. Pelo obturador, a captura não apenas do que era enquadrado, mas principalmente de tudo que não poderia estar presente nela. O retrato da instituição escolar, a produção das ausências. Dentro daqueles muros, "eu, objeto, já não luto” (BARTHES, 2015, p.21).

Éramos todos induzidos à morte através da fotografia. Morte a tudo que pudesse ser nós mesmos. Barthes (2015) questiona a quem pertence afinal a foto: ao fotógrafo ou ao fotografado? O que vejo na foto é que deveria ser não apenas da escola, mas de toda uma geração pós-ditadura pouco acostumada ao seu fim proclamado.

$\mathrm{O}$ ponto que me punge, que me fere, que desperta, suga a atenção e faz a fotografia existir para mim, opunctum - como nomeia e define Barthes (2015) - poderia ser a contradição da expressão aborrecida de uma criança em uma fotografia que seria dada de presente à sua mãe. Meu punctum é sim o batom borrado, mas é para além disso: o grande, orgulhoso e sincero sorriso com meus olhos que dei por detrás das câmeras ao contemplar a meia vitória de minha irmã. Eu vejo um batom vermelho. Eu vejo que vejo. Uma foto é sempre invisível, e como bem lembra Barthes (2015): não é a ela que vemos.

Segui minha dupla existência sem nenhuma expectativa em me surpreender na escola. Eles se ocupavam demais em produzir os melhores alunos, mesmo que nós não fôssemos nós e ficássemos à margem de nós mesmos.

Curiosamente ao final desse mesmo ano, ganhei uma câmera fotográfica de presente de natal. Era a primeira vez que eu havia sido consultada sobre o que queria e não lembro bem por que pedi justo uma câmera fotográfica. Era a estreia em ganhar um presente diferente de bonecas, diferente dos presentes de minha irmã ou das divisões extraoficiais com meu irmão. Nunca li o manual de instruções e apenas muito depois consegui usá-la sem as recomendações de meu pai. Eram dias e dias, semanas e semanas economizando por rolos de filmes e revelações de fotos que, no final das contas, nem eram minhas. Os elogios sobre o enquadramento e o uso da luz eram recorrentes, tudo devidamente de acordo com padrões, um grande feito pra alguém com pouca idade. E assim, continuava a produzir coisas tendo meu olhar conduzido por ecos 
que vinham de muitas partes, ecos internalizados e geravam uma expressão que achava ser minha.

Meu maior brinquedo continuou sendo minha irmã, que têm consigo centenas de fotos de sua infância que posso até classificar como boas, não pela técnica utilizada, mas por retratarem sua espontaneidade e despreocupação diante das lentes. Isso me possibilitava registrar momentos e expressões genuínas, autênticas. Por ser aquela que sempre estava atrás da câmera, conto nos dedos as fotos de minha infância que não sejam de datas festivas. Nunca reconhecia vestígio de mim nas fotografias. Introvertida, mal sabendo que me refugiava sempre para dentro de mim.

Junto com o sexto ano, a timidez vexatória cederia espaço à expansividade de forma lenta e gradual, cederia espaço ao permanente conhecimento de quem eu era e o meu estar à vontade em meu próprio corpo. Descobrir coisas das quais gostava muito e receber méritos escolares por isto era um marco em minha vida escolar, que se tornou menos enfadonha a partir de então. E me tornei uma. Indivisível.

Passava as tardes a contemplar as luzes entre as folhas da copa da mangueira da casa de meus pais, que fora ampliada mantendo-a em seu interior, e onde além de mim, apenas meu irmão mais velho e uma prima-irmã costumavam chegar. Eram tardes de pensamentos livres que nutriam conversas tolas e frutas colhidas do pé. Frutas que alimentaram pactos silenciosos de cumplicidade eterna.

As fotografias que nunca tirei ficaram guardadas em minha memória como um filme não revelado. Eu diria que naquelas em que não estou é onde possivelmente mais vejo minha própria imagem, ainda que nem tenha sido eu a elegê-la. A imagem passa a fazer sentido e ter significado a partir do momento em que me toca, que faz sentido para mim, proporcionando o que Larrosa (2004) chama experiência.

Navegando a esmo na internet, encontro na página de um cineasta algumas fotografias que despertam minha atenção e sou arrebatada por uma delas. Não é a que considero mais bonita e, justo por saber de minhas afeições estéticas, isto me intriga. Um telhado e a copa de um pé de acerolas ou pitangas, custo identificar. Algumas caídas nas telhas de amianto, misturam suas cores. Cinza e vermelho. Punge, prende, fere. Passo dias sem compreender minha vontade de revisitá-la, sempre cedendo, porém. Entro em contato com seu autor, mas decido utilizar dela apenas o que deixa em mim.

Olho para as que não estão prontas para mim e me sinto também olhada por aquelas que não posso alcançar. Não são acerolas ou pitangas, tampouco são apenas mangas. São as folhas, 
é a primavera que deixava na calçada e no telhado todas aquelas flores e sim, é o tão esperado verão e seu gosto de férias, doce, amarelo e dividido com meu compadre, além de irmão, com minha comadre, além de prima. É a telha que piso com cuidado para que a caçula não perceba que estou no meu esconderijo e não chore e me chame para brincar com suas bonecas. Ser a irmã do meio me deu, com o tempo, a qualidade de mediar, sempre dividida, sempre fatalmente desagradando alguém ao fazer uma escolha.

Sou eu, fora de foco, fora de alcance no topo de uma árvore que coincidentemente morreu atingida por uma praga pouco depois que meu irmão e eu saímos de casa já adultos. Mas a morte não a mortificou. E ela se faz presente em uma imagem em que nem aparece, em que nem se disfarça em tolas frutas delicadas. Ela está no telhado que pisei sob sua sombra, na temperatura que deixa em meus pés, na memória do gosto da manga que não vende no mercado, naquelas que deixei aos passarinhos ou que ao esperar para o outro dia perdi para os morcegos. Nas que comi sem modos, sem focos. Na textura das folhas secas sobre as quais deitei para olhar a árvore de outro jeito. É meu pequeno fulcro.

E por isso o que vejo nessa fotografia não está nela. Está na minha versão favorita dos meus dias. Está encarnada em meu corpo. Está em mim.

\section{$E x$-posições}

Se há uma desumanização em curso, quando não houve?

Por ser compreendido e destacado com um valor estimado, um corpo silencioso é confundido com passivo, conformado. Seguir a composição de silêncios induzidos pode estar, porém, bem distante de qualquer espécie de silenciamento. E a despeito dos procedimentos de uma produção, não há garantias de seus efeitos quando o que está em jogo é o humano.

Ao menor sinal de autoritarismos, a dúvida segue aniquilada de ser suscitada, e é substituída por certezas e padrões. Mal contidas em sua interioridade, as maneiras de compor silêncios aguçam outras percepções, expandem os modos do corpo ser afetado. Ampliam os modos de ouvir, de sentir na pele, intensificam os modos de ver, de reverberar.

Não há aqui intenção de minimizar a importância de empregar a devida atenção aos procedimentos de captura e supressão da formação e das possibilidades do corpo, mas sim, de desviar o olhar àquilo que perde o foco, ao movimento que se revela como um borrão. 


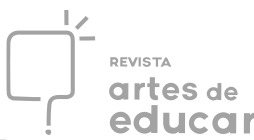

Movimento imprevisível com o qual o corpo se manifesta e se desenvolve por outras vias, em outras potências.

Uma relação entre corpo e humanização é uma relação íntima, na qual causas e efeitos se imbricam. Se o corpo é elemento material fundamental para ser humano, é também nele e através dele que seu vir a ser, suas virtualidades adquirem ou não mais realidade quando em contato com outras virtualidades e realidades.

\section{Corpo vibrátil, corpo harmônico}

O que silencia um instrumento musical de vibrar em ressonâncias e frequências quando atingido por outro ressoar é o toque no que vibra; o ato de impedir a vibração de uma frequência musical é o gesto impeditivo de não deixar que algo lhe afete como deveria ser afetado. De não deixar que a consequência desse afeto em seu corpo, movimente o corpo, o faça mover da forma que só ele o pode. Vibrar é estar vivo. Só afeta e é afetado quem, de fato, se faz movimento. Mover-se é acessar e ser acessado a outros movimentos em si. Quando eu movimento, o gesto me move, o movimento gesta a mim.

Em uma apresentação musical, como numa orquestra sinfônica, há uma quantidade enorme de instrumentos acústicos. Sendo eles tocados em intensidades, durações, perspectivas e singularidades diferentes. O conjunto da orquestra tocando não é o somatório do som de cada instrumento em gesto. Um naipe de quarenta violinos tocando exatamente a mesma nota não soa como um violino multiplicado por quarenta em potência sonora (uma lógica exata e racional). Existem ali, frequências que provocam ressonância e vibração em toda matéria, inclusive no ar, e essas frequências, quando os instrumentos tocam em conjunto, fazem vibrar em todos os instrumentos, as notas que ressoam de um único harmônico. O harmônico é o acontecimento de vibração em uma determinada frequência que vibra outras frequências. $\mathrm{O}$ harmônico é o desejo se efetuando no corpo, como o resultado de um desejo do afeto.

A frequência aqui, como potência de afeto, de pensamento do corpo, que atravessa os corpos, evoca e provoca os desejos nos corpos. Por isso, uma mesma nota vibra outras, em um mesmo instrumento. Não é a partir da intencionalidade da vibração que o harmônico ressoa ele ressoa porque ele tem de se efetuar como força, como potência de um corpo intensivo. A vibração de uma nota mi, por exemplo, em um desses quarenta violinos, vai fazer com a mesma nota mi, e a nota lá, e a nota ré, e a nota sol sustenido, ressoe em alturas diferentes, em outros 
instrumentos, mesmo sem tocá-los. Um gesto reverberando em afetos e produzindo novos movimentos em corpos; o desejo sendo evocado pelo estado de força e potência que a frequência provoca. O que vibra nos corpos. Por isso nenhuma gravação - que é uma representação escrita da onda sonora, jamais vai dar conta do que é o fazer musical ao vivo. A lógica exata representada na escrita sonora não dá conta de um único gesto vibrátil ao vivo; a lógica como método sendo exata nas suas significações e na matemática de suas afirmações jamais dará conta do pensar corpo de uma singularidade educacional.

A ressonância, que é provocada quando os instrumentos tocam em conjunto, ou mesmo um próprio instrumento solo, em um acontecer real, é a unidade originária do fazer artístico que não é nem a qualidade da nota musical, nem a quantidade de instrumentos, e nem uma virtude essencial da música. Mas sim a qualidade do instrumento na sua feição. A fabricação do instrumento musical é tão melhor quanto mais harmônicos ressoarem e provocarem, em si mesmo, ressonância dos harmônicos que em sua madeira ressoam ao tocar.

O conhecimento, tal qual o sentimento, é sempre singular ao sujeito. Mas existe uma força na coletividade, enquanto vibração e frequência, ao que ressoa. E é a partir do encontro dos corpos que .... ressoa e se efetua como força, como potência no sujeito. A qualidade dos corpos afetivos aqui não nos diz no resultado consonante das suas afecções ativas, mas na quantidade de ressonâncias que o seu corpo é capaz de comportar como efetuação de si. É ao aumentar suas possibilidades de vibrações, de frequências e de sentidos. Não é uma mudança de perspectiva, como se costuma dizer, no intelecto dos sujeitos. É uma mudança de perspectiva de um pensar corpo e que é involuntária e arbitrária. Quanto mais sinto, mais me torno uma potência de sentir; quanto mais me torno uma potência de sentir, mais eu sinto. Na unidade das afecções que sou atravessado e atravesso na medida em que meu corpo se torna forte. Se torna um corpo de ação. Como criação contínua do corpo vibrátil, que ressoe harmônicos e os faça ressoar. A harmonia é sempre, na música e fora dela, unidade sonora. Unidade que produz sentido.

\section{Considerações provisórias}

Um espaço tempo de aula com trinta alunos estudando um mesmo conteúdo não é, nem jamais será, a redutibilidade de um aprendizado multiplicado por seu número. Há indefinidas quantidades de possibilidades, vivências, traços culturais, pensamentos, questões e potências. 
A sala de aula não se diz ao somatório de conhecimento dos alunos como amostragem exata, como não são os violinos. É o pensar corpo do sujeito que faz vibrar o conhecimento. $\mathrm{O}$ aprendizado, assim como a ressonância, acontece na unidade. E a educação, como potência de um existir vibrátil, acontece na unidade do gestar educação, dentro e fora da sala de aula, de forma singular a cada sujeito. E na força da coletividade, enquanto vibração e frequência, ao que ressoa e aos que ressoam.

Se é um fato que há uma desumanização em curso e se essa desumanização se apresenta em doses ora menos, ora mais intensas, é inevitável pensarmos em uma educação que considere o processo de humanização como fundamental para o tipo de ser humano que se pretende.

Ao suscitar marcas e alguns procedimentos de negação do corpo, podemos perceber como a penetração da cultura autoritária e a construção da subalternidade se mostraram em muitas vezes por gestos sutis, na economia de gestos e a diferença como algo a ser abolido. Contudo, se essa sutileza foi responsável por promover uma economia inconfessável, torna-se indispensável perceber seus novos arranjos despudorados, e mais ainda: imprescindível que nos debrucemos sobre os possíveis, sobre as dimensões de expressões.

Retornando aos autores e à fala que serve como pré-texto, as características destacadas funcionam como efeitos, como força harmônica e vibrátil: uma desumanização em curso exige modos de nos posicionarmos diante do mundo como os seres inacabados que somos, como os seres também em curso. Os traços essenciais da humanidade como o senso de beleza, a percepção [...] destacados como essenciais, como vetores desorganizadores da ordem destinada. São exercícios de ver, desver, transver o mundo, desarranjadores da métrica pretendida. Um corpo individual que se relaciona e se ramifica no corpo coletivo, que embaralha suas fronteiras e amplia suas formas de intervenção no mundo. Uma força que reverbera na própria incompletude e move a outros destinos, a outras possibilidades: de ser outro, de ser mais. De ser mais humano.

Se poucas coisas se aproximam mais do ser humano que o corpo com o qual e no qual se fazem os exercícios em ser humano, resta-nos interrogar como esse corpo permanece em estado vibrátil. Mais: resta-nos o movimento, a continuidade e não a interrupção de sua vibração, de sua ressonância.

Um corpo que se expõe é também um corpo ex-posto e se coloca à luz e se atira em ser algo para, tão logo, tornar-se outro, tornar-se mais. Em movimento, como criação contínua de si, corpo vibrátil, que ressoe harmônico. Nas brechas e nos encontros de sentidos, se são indispensáveis para uns, são indispensáveis para todos. 


\section{REFERENCIAS}

BARTHES, Roland. A câmara clara: nota sobre a fotografia. Rio de Janeiro: Nova Fronteira, 2015.

CÂNDIDO, Antônio. “O direito à Literatura”. In: Vários escritos. São Paulo: Duas Cidades, 2017.

FOUCAULT, Michael. Vigiar e Punir: nascimento da prisão. 42. Ed. Petrópolis, RJ: Vozes, 2014.

LARROSA, Jorge. Ensaio e escrita acadêmica. Revista Educação e Realidade, 28 (2):101 $115, \mathrm{jul} / \mathrm{dez} 2003$.

Autêntica Editora, 2017.

Linguagem e Educação depois de Babel. $2^{a}$ edição. Belo Horizonte:

SANTOS, Boaventura de Souza. A crítica da razão indolente contra o desperdício da experiência. Para um novo senso comum: a ciência, o direito e a política na transição paradigmática - $8^{\mathrm{a}}$ edição. - São Paulo: Cortez, 2011.

\footnotetext{
${ }^{\text {i }}$ Doutoranda do PPGE-UFF sob a orientação da professora Dra. Carmen Lucia Vidal Pérez, na linha Estudos do cotidiano da educação popular. Brasil. E-mail: ramos.renatafernandes@ gmail.com. https://orcid.org/0000-00027065-5008

ii Mestrando do PPGE-UFRJ sob a orientação do professor Dr. André Bocchetti, na linha Currículo, docência e linguagem. Brasil. E-mail: thomaz.baldow@gmail.com. https://orcid.org/0000-0002-8029-1770

${ }^{3}$ Fala da professora Dra. Waldenez Oliveira, durante o III Seminário temático Educação Popular AnPed. 50 anos da Pedagogia do Oprimido: atualidades e desafios do pensamento Freiriano. Universidade Federal Fluminense. Setembro, 2018.

${ }^{4}$ Texto parcial e integrante de dissertação de mestrado, defendida e aprovada (2017) com o título: "Corpo e imagem como heterotopias: mortificações e imortalizações do cotidiano escolar".

5 Amélia como referência à mulher dona de casa exaltada pela música "Ai que saudades da Amélia", de Mario Lago e Ataulfo Alves, 1941.

${ }^{6}$ Da obra Peanuts, de Charles M. Schulz. Charlie Brown, protagonista de desenho animado americano, ao falhar no que tenta fazer, dispara a frase "Que puxa”, como uma lástima.
} 